\title{
O impacto do empobrecimento na velhice
}

Edneia Salviano da Silva Santos*

Beltrina Corte*

Resumo: Esta é uma pesquisa qualitativa, baseada em entrevistas com a seis pessoas de 59 a 82 anos, dois homens e quatro mulheres, que foram ricas e em decorrência de um determinado evento se viram empobrecidos na velhice. Partimos da hipótese de que tais sujeitos negaram tal possibilidade durante toda a vida e não procuraram proteger-se financeiramente, fato que acabou por agravar ainda mais o impacto sofrido diante do evento de vida negativo. Os dados levantados permitiram concluir que o impacto ocasionado pelo empobrecimento em idosos que gozavam de uma situação financeira confortável foi sentido em maior ou menor intensidade, dependendo do tipo de trajetória de vida que cada um construiu. Aqueles que cultivaram uma rede social apoiada em múltiplos eixos demonstram possuir uma maior capacidade de adaptação aos eventos estressores provenientes das reviravoltas do projeto de vida e aparentam uma facilidade maior em aceitar e assimilar as lições da vida, reinventando-se.

Palavras-chave: empobrecimento, velhice, idosos, gerontologia, envelhecimento.

Psicóloga pela Universidade Paulista (Unip), especialista em terapia familiar e mestre em Gerontologia pela Pontifícia Universidade Católica de São Paulo (PUC-SP). E-mail: edneia-02@uol.com.br

Doutora em Ciências da Comunicação pela Escola de Comunicação e Artes (ECA) da Universidade de São Paulo (USP), docente do Programa de Estudos PósGraduados em Gerontologia da PUC-SP, coordenadora executiva do Website www. portaldoenvelhecimento.net e editora da revista Kairós. E-mail: beltrina@uol.com.br 


\section{The impact of impoverishment on old age}

Abstract: This qualitative research was developed in which six people (two men and four women), between the ages of 59 and 82 , were interviewed. These individuals used to be rich and, due to some event, became impoverished in old age. The hypothesis that guided the study was that these subjects denied that possibility during their entire life and did not think of financially protecting themselves; this fact aggravated the impact they suffered due to the negative life event. The collected data allowed one to conclude that the impact of impoverishment on elderly individuals who used to have a good financial situation was felt with less or more intensity depending on the type of life trajectory constructed by each subject. Those who cultivated a social network supported by multiple axes showed greater capacity to adapt to stressful events deriving from changes in their project of life and seem to have greater facility to accept and assimilate life's lessons, reinventing themselves.

Keywords: impoverishment, old age, elderly individuals, gerontology, aging.

\section{Introdução}

Atualmente, observa-se um aumento no número de termos utilizados para designar o idoso e a velhice. Um dos muitos critérios de definição para a categoria idosa, e talvez o mais utilizado pela comunidade científica, é a idade cronológica. Para tanto, a Organização Mundial de Saúde (OMS, 1984) considera idosa toda pessoa acima de 60 anos que resida em países em desenvolvimento ou acima de 65 anos para os residentes em países desenvolvidos.

No Brasil, a Política Nacional do Idoso (Lei 8.842, de 4 de janeiro de 1994, Cap. 1, art. 2) adotou o limite etário de 60 anos para definir quem seria considerado idoso.

Culturalmente, amadurecer pode descrever tanto fatores positivos, quanto negativos. Enquanto aspecto positivo, denota certo grau de excelência ou de virtude, sugerindo que o adulto 
maduro é aquele que possui as qualificações necessárias para atuar como conselheiro, modelo, fonte de informações sobre fatos e procedimentos. No sentido pejorativo, o termo maduro pode significar que o sujeito é menos bonito, menos competente, pouco produtivo, menos capaz intelectualmente (Neri; Freire, 2000).

No aspecto social, o termo adulto maduro pode sugerir certo tipo de padrão de comportamento esperado. Trata-se da descrição de uma pessoa experiente, bom ouvinte, que gosta de ensinar o que aprendeu, sempre demonstrando prudência e tolerância em "seus conselhos" (Neri; Freire, 2000).

Já o termo terceira-idade nasceu na França, em meados da década de 60 , com características socioeconômicas, tendo sido utilizado para designar o fim da produtividade econômica, ou melhor, a aposentadoria. Atualmente, tem sido utilizado para referir-se à faixa etária entre a vida adulta e a velhice (Neri, 2001a).

Na percepção de Neri e Freire (2000), a diversidade de termos tem como função primordial encobrir o preconceito associado ao idoso e à velhice. Esses autores defendem o uso dos termos "velho" ou "idoso" para designar pessoas idosas, "velhice" para referir-se à última fase do ciclo vital e "envelhecimento" para descrever o processo de mudanças físicas, psicológicas e sociais que ocorrem desde o nascimento e tornam-se mais evidentes, aproximadamente, a partir dos 45 anos. Segundo Neri (2001a, p. 27),

biologicamente falando, o envelhecimento compreende os processos de transformação do organismo que ocorrem após a maturação sexual e que implicam a diminuição gradual da probabilidade de sobrevivência.

No entender de Hollis (1995), o envelhecimento é mais uma experiência psicológica do que um evento cronológico. 
Tal autor argumenta que na última fase do desenvolvimento humano, muito mais do que enfrentar as transformações físicas, o indivíduo depara-se com questões relativas à sua identidade (pessoal e social) e o sentido da vida e, diante desse contexto, precisa reorganizar aspectos de sua personalidade para poder adaptar-se às mudanças e limitações características do processo de envelhecimento.

Diante da diversidade de definições encontradas na literatura, concordamos com Paschoal (2004) ao considerar que o envelhecimento é uma experiência heterogênea, na qual cada pessoa pautará sua vida de acordo com padrões, normas, expectativas, desejos, valores e princípios distintos e pessoais.

Pesquisando adultos e idosos entre 52 e 92 anos, Veloz, Nascimento-Schulze e Camargo (1999) levantaram três categorias principais de representações sociais sobre o envelhecimento: 1) a perda dos laços familiares e da identidade física; 2) a perda da capacidade de trabalho; e, 3) o desgaste natural. As representações relativas à perda da capacidade de trabalho consideram a aposentadoria como o começo do desengajamento social, como um acontecimento intermediário entre a vida e a morte.

Conforme ressalta Peixoto (2004b), entre outros fatores, a aposentadoria traz ao idoso uma degradação de sua condição de vida, uma vez que a perda financeira não permite manter um nível de vida próximo àquele vivenciado no período de atividade.

Com base em tais argumentações, podemos hipotetizar que a queda no nível socioeconômico decorrente da aposentadoria pode ser um dos muitos fatores que a transforma numa espécie de anúncio de morte próxima. 
Diante de tal quadro surgiu, então, o interesse em estudar qual seria o impacto do empobrecer na velhice para idosos que gozaram de uma situação financeira abastada durante toda a vida. Foi, então, desenvolvida uma pesquisa qualitativa com pessoas que, em decorrência de um determinado evento, viram-se empobrecidas na velhice. ${ }^{1}$

A opção pela abordagem qualitativa se deu porque consideramos, juntamente com Debert (1996), ser este tipo de estudo um método mais adequado para desmistificar pressupostos baseados em imagens negativas sobre 0 envelhecer.

Utilizamos um questionário de identificação dos sujeitos composto por sete perguntas que objetivavam levantar informações de identificação dos participantes (sexo, idade, escolaridade, profissão, estado civil). Fizemos uso de um roteiro de entrevista aberta, composto por duas questões que nortearam a coleta dos dados de forma não diretiva para que os sujeitos relatassem suas experiências com total liberdade de expressão: a) O que significou a perda do dinheiro em sua vida? e b) Como você lidou com essa situação?

Utilizamos a entrevista aberta porque a verbalização através de um discurso pode fornecer indicações mais precisas sobre projetos individuais. May (2004, p. 145) também fala da importância das entrevistas, pois elas "geram compreensões ricas das biografias, experiências, opiniões, valores, aspirações, atitudes e sentimentos das pessoas".

No total, foram realizadas seis entrevistas abertas ${ }^{2}$ (realizadas na casa de cada um), com dois homens e quatro

Este estudo foi tema da dissertação de mestrado de Edneia Salviano, defendida na PUC-SP em 2008.

2 Utilizamos também a técnica do Diário de Campo para anotar as descrições minuciosas e intimistas da pesquisadora logo após cada entrevista. 
mulheres, com idades entre 59 e 82 anos. Esses sujeitos foram selecionados ao acaso, de acordo com o critério de inclusão preestabelecido de ser alguém que tenha gozado de uma situação financeira confortável durante toda vida e, por algum tipo de ocorrência, empobreceu na velhice. Dentre os selecionados, ${ }^{3}$ quatro deles eram participantes de um grupo terapêutico de terceira idade e os outros dois foram indicações.

Optamos por dar destaque maior à questão de melhores condições de vida do idoso que, além de enfrentar as mudanças de sua fase de desenvolvimento, sofre com a perda de sua condição socioeconômica. Com o objetivo de levantar dados que possam contribuir para as políticas de prevenção e atendimento psicoterapêutico de idosos nas mesmas condições, também descrevemos quais as estratégias de enfrentamento utilizadas pelos idosos e quais os resultados por eles obtidos.

\section{Trajetórias de vidas}

A trajetória de vida pode ser entendida como o conjunto de eventos que estrutura a vida de uma pessoa. Tal estruturação é influenciada, em maior ou menor grau, pelas informações que perpassam a sociedade moderna como, por exemplo, a idade média para casar, para ter um filho, para se aposentar e assim por diante (Born, 2001).

Passaremos agora a descrever as principais características de cada um dos seis entrevistados.

3 Os sujeitos foram esclarecidos de que seriam livres para participarem ou não da referida pesquisa, sua participação não acarretaria custos a ele e seus nomes seriam trocados. Todos aceitaram participar da pesquisa e assinaram em duas vias o Termo de Consentimento Livre e Esclarecido elaborado de acordo com as determinações previstas na Resolução 196/96 do Conselho Nacional de Saúde. 
Alex, 59 anos, viúvo, é formado em Direito e realiza um trabalho voluntário como advogado conselheiro em um escritório de advocacia de um antigo amigo. Também é formado em Administração de Empresas pela USP. Começou a trabalhar em empresas multinacionais pelo inglês fluente. Conta que $o$ pai tinha uma grande loja de material elétrico e foi trabalhar com ele para assumir a loja. Viveu durante muitos anos bem: "O Alex daquela época tinha muito dinheiro, muitos amigos ricos, apartamento, lancha. Hoje, eu recebo uma pensão do INSS por invalidez".

Sandra, 66 anos, viúva, é formada em Artes Plásticas e trabalha como estilista. Trata-se de uma senhora que aparenta ser mais jovem do que realmente é, de cabelos louros na altura dos ombros, aproximadamente $1,60 \mathrm{~m}$. Seu olhar é um misto de acolhimento e curiosidade. Sandra iniciou contando que sua mãe era estilista e seus pais tinham uma fábrica de confecção de roupas. Tinha uma vida de luxo. Casou-se com um rapaz pelo qual era apaixonada e continuou a ter uma boa vida até ficar viúva. A partir daí, tudo mudou em sua vida. O marido havia contraído dívidas que não conseguiu saldar e, com sua morte, os credores apareceram e, depois disso, chegou um dia em que ela não tinha nem energia elétrica em casa, pois havia sido cortada por falta de pagamento. Sandra narrou todos esses e outros acontecidos sem rancor ou ressentimentos, mas como uma forma de crescimento pessoal. Afirmou que sofreu muito com tudo, mas que cresceu também. Têm 2 filhos casados que estão próximos e ajudam como podem.

Roseli, 62 anos, viúva, cursou o Ensino Fundamental e atualmente dedica-se às prendas domésticas, não sendo a provedora de seu lar. Roseli manteve o foco no assunto e percebemos como ainda era difícil tratar de tais questões. Em várias ocasiões ela se emocionava, tomava um gole de água, respirava fundo e começava a falar sem em momento algum 
sair da discussão da entrevista, mas deixando evidente como a questão ainda era difícil para a sua vida.

Marcos, 65 anos, casado, é formado em Sociologia e não se coloca como o provedor de sua família. Marcos se expressou muito bem, demonstrou ser um homem inteligente, mas sem força para lutar por seus sonhos. Durante a entrevista era possível ouvir um barulho vindo da cozinha, que parecia ser da empregada nos afazeres domésticos. Sua esposa estava trabalhando naquele momento. Marcos fica em casa, pois já se aposentou. Conta que ocupa o tempo com leitura ou com a visita dos netos. Tem duas filhas, uma médica e a outra promotora. Referiu-se às filhas com muito orgulho.

Eliana, 80 anos, viúva há 20 anos, cursou o Ensino Fundamental. Atualmente trabalha como vendedora em uma loja de roupas e não se classifica como provedora de seu lar. É uma senhora que aparenta ter cerca de 70 anos. No momento, trajava uma calça bege social e blusa de malha que a deixavam muito clássica e elegante. É magra e seus cabelos são curtos. Usa uma bengala, pois sofreu um acidente.

Eliana e seu marido, já falecido, são húngaros. Vieram muito pequenos para o Brasil e as pessoas que pertenciam à colônia húngara só podiam casar entre eles. Quando se casou, tinha 20 anos e seu marido 26. Tiveram um casal de filhos, sendo que o rapaz morreu num acidente aos 26 anos. Eliana relatou tal fato como sendo o "pior episódio de sua vida", a ponto de várias vezes durante a entrevista voltar a falar sobre o assunto. O marido teve um AVC, ficou 10 anos doente e ela cuidou dele durante todo esse período. Com a doença do marido, o dinheiro foi diminuindo.

Outro período difícil para Eliana foi um acidente que sofreu há alguns anos e cujo tratamento se prolonga até os 
dias atuais. Mesmo assim, ela e a filha visitaram a Hungria recentemente, que era seu sonho.

Eliana demonstrou ser uma mulher forte e dedicada, falou do tema proposto de uma maneira serena e afirmou que aprendeu a conviver com os infortúnios da vida.

Helena, 82 anos, viúva, cursou somente os quatro primeiros anos do Ensino Fundamental e atualmente dedica-se às prendas domésticas. Ao término da entrevista Helena fez questão de nos mostrar seu apartamento, cômodo por cômodo, sendo a única dos seis entrevistados a proceder de tal forma. $\mathrm{O}$ apartamento possui dois dormitórios bem espaçosos, uma sala grande, cozinha e banheiro, tudo mobiliado de forma simples, mas bem organizado e limpo.

Helena é uma senhora lúcida, afetiva e muito simples. Mora sozinha desde a morte do marido há 5 anos, mas os filhos e netos sempre a visitam ou ligam constantemente. Não assumiu em nenhum momento seu poder aquisitivo anterior como sendo de alguém rico, apesar de já ter morado em ruas nobres da cidade de São Paulo, como a Dr. Arnaldo e a Cristiano Viana. Durante a entrevista, sempre afirmava: "nunca fui rica e nunca fui pobre" e falou de sua fé em Deus e de como sua vida foi e é baseada em cima dessa fé.

Com base nos recortes dos relatos de cada entrevistado, observamos que, ao contar a sua trajetória de vida, cada um focalizou os eventos que considerou importantes para a constituição de sua identidade social anterior e atual.

Joan Lavid e Susan Griffin, citados por Walsh (2005), afirmam que o ato de contar sua história possibilita o conhecimento e a construção de uma identidade coerente e conectada com o social, pois quando as histórias são contadas e os segredos se revelam, a vida se torna mais clara para o narrador. 
Já Born (2001, p. 243) argumenta que estudar a trajetória de vida é fundamental para desvendar as relações existentes entre mudança social e mudança de status. A autora considera que

os indivíduos desenvolvem perspectivas de vida e negociam variações ao longo de suas vidas, tendo como referência a mudança de status que une várias áreas e estágios da vida. As mudanças de status conferem - como momentos cruciais - uma estrutura à trajetória de vida.

Ao pesquisar indivíduos de diferentes camadas sociais, Velho (1975) concluiu que a trajetória de vida de cada sujeito determinará como este encara e entende o mundo e as mudanças que o circulam. Observou ainda que pessoas pertencentes à mesma categoria socioeconômica optavam por estilos de vida contrastantes, dependendo de sua trajetória de vida pessoal.

Os relatos dos entrevistados sobre o impacto da perda financeira em suas vidas evidenciam o quanto tal perda provocou mudanças nas relações sociais que cada um estabeleceu e, conseqüentemente, mudanças de suas identidades sociais.

\section{O impacto da perda financeira e a importância da rede social}

O empobrecimento machuca por dar uma insegurança... porque não tem outros recursos além das aposentadorias. É uma dor realmente muito grande porque tudo que eu tinha planejado na vida, mudou. Meus planos todos desmoronaram, e eu tento, a todo o momento, com muita dificuldade, reconstruir. (Alex)

Sabe quando você tem todo tipo de perda, de uma vez? Sabe te arrancarem a pessoa que você mais gosta, com todos os bens. Eu tive perda total de bens. Desespero total.... Quando meu marido 
faleceu... tive que arcar com coisas de engenharia, que não tinha nada a ver com a minha vida. Enfim, eu perdi tudo. Carros, tudo, tudo. Eu e meus filhos, que moravam comigo, nós tivemos que ir, cada um, buscar a sua vida, o seu sustento. Meus filhos, cada um casou, muito drasticamente, meio que fugindo dos problemas. Eu sempre fui muito espiritualista, sempre achei que dinheiro era uma coisa secundária. Achava um absurdo a luta pelo dinheiro. Daí a vida me passou essa rasteira. (Sandra)

Esse tema é meio sofrido para mim, foi um desmoronamento total. Eu não sentia chão, no momento que eu soube e fui me adaptando a essa vida, me reeducando, com essa vida de depender das pessoas, que é horrível. Ficou lamentável, porque tudo é você com seu talão de cheque..., você não é você, você é o seu cheque. A experiência foi dura, muito dura. Muito difícil me adaptar, entender ao redor, me entender, entender meus filhos, mas eu acho que ainda não aprendi tudo. Meu mundo desmoronou. Em todos os sentidos. (Roseli)

Para Alex, Sandra e Roseli, a situação financeira e social anterior não tinha limites de gastos, caprichos ou vontades. Alex, como provedor de sua família, preocupava-se em dar "o melhor" e demonstrava que "era insuperável". Sandra e Roseli contavam com seus maridos como administradores das finanças familiares, ocupando-se apenas com "limites concernentes ao dinheiro". Atualmente, todos demonstram a preocupação com seu meio de subsistência, sendo que Alex foi o único dos três entrevistados que se preocupou em pagar o INSS e garantir uma pensão. Sandra procurou adaptar-se à nova situação, buscando aproveitar suas habilidades artísticas da melhor forma possível. Roseli, por sua vez, não obteve o mesmo êxito e relata sua dificuldade em mudar seu comportamento quando afirma que experimentou trabalhar, mas não deu certo, pois não tem qualquer habilidade específica.

Claro que é um baque, você querer fazer uma coisa e não ter o dinheiro para fazer... por exemplo, férias. A gente sempre saía de 
férias, e chega uma hora que não dá, porque o dinheiro não dá. Acho que o que mais me afeta, para mim, é ver que ela [esposa] se machucou um pouco. Esse foi o lado mais doído para mim. (Marcos)

Minha vida é tão restrita. Não é um cabedal de sair para lugares de alta sociedade, não tenho amigas. (Eliana)

Não gosto de dever, não gosto que meus filhos devam. Não gosto de dívida, mas dinheiro, para mim, é o suficiente, aquilo que eu preciso. Não quero que falte, é claro, mas também não fico doida por dinheiro. (Helena)

Já Marcos, Eliana e Helena evidenciaram em seus relatos uma percepção da situação financeira e social anterior como resultante de uma vida profissional bem-sucedida e do esforço em crescer e melhorar a cada dia. Não reconheciam sua condição financeira como algo além do ter um bom salário e uma casa boa. Portanto, não só sentiram menos a queda do padrão anterior, como também demonstraram preocupar-se com essa possibilidade e procuraram garantir algum tipo de renda que os sustentassem no futuro. Marcos credita sua renda atual às ações de sua esposa que sempre trabalhou e buscou "economizar parte do dinheiro". Eliana administrou a venda de imóveis de maneira a garantir um apartamento e ainda guardar algum dinheiro da venda do imóvel anterior. Helena afirmou que seu dinheiro "é suficiente", podendo até ajudar a igreja. Isto porque conta que seu marido sempre pagou o INSS.

Portanto, podemos observar que o relato da trajetória de vida de cada entrevistado nos permite dividi-los em dois grupos distintos: o primeiro, composto por Alex, Sandra e Roseli (Grupo A), não conhecia limitações de gastos até sofrer o impacto da perda financeira, logo não se preocupou com tal possibilidade. O segundo, do qual fazem parte Marcos, Eliana e Helena (Grupo B), é aquele que cresceu devido ao seu esforço no trabalho e visualizavam a possibilidade de não contar com a mesma renda em momentos diferentes da vida. 
Observamos que para Alex, Sandra e Roseli o advento da perda financeira trouxe à tona sentimentos de insegurança, desespero, desmoronamento total. Alex relatou que seu projeto de vida mudou radicalmente. Sandra contou que sofreu todo tipo de perda, já que o falecimento de seu marido foi o fator desencadeante de todo o resto. Sandra focalizou em seu relato sua percepção de que "você é o que você possui" e, por conta de tal fato, perdeu sua rede de amizades por não mais poder participar dos mesmos programas, nem ter "os mesmos papos".

Marcos, Eliana e Helena relataram suas experiências de maneira mais branda que o grupo anterior. A percepção de Marcos sobre a perda do emprego recai sobre sua identidade social, gerando o seguinte questionamento: "Já que não sou o provedor, quem sou eu? Não sou ninguém". Eliana, assim como Sandra, sentiu a perda de sua rede de amigos, fator este que restringiu sua vida. Helena pareceu ser a que menos sofreu o impacto da perda, visto que afirmou não "dar excessivo valor ao dinheiro".

De modo geral, os projetos de vida de cada entrevistado sofreram mudanças, contudo o primeiro grupo demonstrou ter sido mais afetado em sua estrutura social e emocional, em comparação ao segundo grupo. Tal fato pode ser explicado pelas diferenças de trajetória e projetos de vida dos sujeitos desta pesquisa.

De modo geral, os entrevistados encontraram apoio entre seus familiares, amigos mais próximos e membros de comunidades religiosas ou clubes sociais.

Alex afirmou que buscou o apoio da Igreja e que seus amigos não o abandonaram na hora em que ficou pobre. Eliana mantinha o contato com suas raízes húngaras e ainda aproveitava tal vínculo para ajudar na colônia de idosos, de 
senhoras húngaras. Marcos e Helena destacaram a função essencial de seus familiares em suas redes sociais.

Por outro lado, Sandra e Roseli pareciam ser aquelas que mais sofreram perdas em sua rede social. Sandra considerava que mantinha apenas dois ou três amigos que acreditava serem "amigos fiéis", mas deixava clara sua crença de que "não podia contar com a ajuda de ninguém, nem mesmo da família".

Tanto Sandra quanto Roseli experimentam sentimentos negativos quando aceitam a ajuda de seus parentes. A ajuda da família é percebida por ambas como uma espécie de agressão à identidade social, porque denuncia a precária condição financeira vivenciada no momento.

Alex, Marcos, Eliana e Helena compartilham de uma visão totalmente distinta no que se refere à presença da família em suas vidas e essa visão positiva contribui significativamente para o aumento da capacidade de enfrentamento de situações negativas, o que resulta em menos sofrimento ante o advento da perda financeira. Outro fator importante a ser considerado em nossa análise diz respeito à vivência da espiritualidade, sendo que apenas Roseli não fez nenhuma menção a esse tema. Todos os outros entrevistados demonstraram algum tipo de vivência relacionada à espiritualidade.

De modo geral, os relatos demonstraram um sentimento de estar protegido pela crença em algo maior. Marcos afirmou que acredita na bondade inerente à humanidade. Alex procurou praticar a religião católica e já havia relatado anteriormente que recebeu muito apoio de sua igreja e dos padres. Sandra, Eliana e Helena citaram Deus e Jesus como fonte de proteção e conforto espiritual.

Podemos hipotetizar que experimentar a espiritualidade influencia não só a forma como a pessoa enfrenta a 
situação atual, mas também o modo de encarar o futuro desconhecido.

Alex e Sandra, que relataram algum tipo de vivência espiritual, não demonstraram temer o futuro. Alex afirmou: "sinto-me seguro por crer em Deus". Roseli, que não fez referências a nenhum tipo de crença espiritual ou religiosa, mostrou-se temerosa em relação ao futuro e novamente afirmou sua descrença e mal-estar em relação ao apoio de sua família. $O$ fato de experimentarem a descrença nas pessoas - quer da sua família, quer do seu círculo de amigos -, e não demonstrarem apoiar-se em uma vivência da espiritualidade, fez com que a perda financeira assumisse características de catástrofe insuperável, impossibilitando que eles desenvolvessem um novo projeto de vida.

É importante destacar o relato de alguns entrevistados sobre o papel da terapia como espaço de auxílio na reconstrução do projeto de vida e na externalização e elaboração dos sentimentos precipitados pelas mudanças vivenciadas.

Os relatos demonstram que o espaço terapêutico é percebido e vivenciado como ponto de apoio, de aprendizagem e de crescimento pessoal, no qual é possível "expor idéias" e entender sentimentos intrínsecos, de modo a poder (re) estruturar a saúde mental.

A análise realizada até então permitiu afirmar que, a partir do momento em que Roseli sofreu a perda de sua condição financeira, perdeu também sua identidade social e passou a restringir sua rede social aos familiares, os quais foram pouco amistosos ou dispostos a ajudar em sua reconstituição. Desta forma, ela não conseguiu visualizar a possibilidade de reconstrução de seu projeto de vida.

Enquanto Alex e Sandra demonstraram uma busca pela maturidade e um aproveitamento da adversidade para 
modificar o projeto de vida de modo a poderem adaptar-se à nova situação, Roseli evidenciou em seu relato toda a sua confusão de sentimentos e sua percepção de que ainda era "jovem".

Os relatos anteriores de Marcos, Eliana e Helena demonstraram que o projeto de vida de cada um já trabalhava com a possibilidade de oscilação financeira, portanto não experimentaram a necessidade de realizar grandes mudanças nos planos, fato que pode ser responsável por todos eles não mencionarem o que aprenderam com a perda financeira.

Importante destacar que o grupo de Alex, Sandra e Roseli ainda sonham com a situação financeira abastada do passado. Alex e Sandra, mesmo demonstrando seu movimento em busca da adaptação à situação atual, ainda anseiam, tanto quanto Roseli, poder viver uma vida com menos restrição.

\section{Reconstrução do projeto de vida}

A velhice é um fenômeno multifacetado no qual, paralelamente aos fatores biológicos, encontram-se variáveis socioculturais e históricas, que resultam em uma pluralidade de formas de se viver o processo de envelhecimento. Alguns autores, entre eles Mercadante (2005), afirmam que estudar a velhice é uma questão complexa, concordando com Edgar Morin, que explica que algo é "complexo" quando indica dificuldades para a sua explicação:

Implica, conseqüentemente, que não há uma resposta simples a ser buscada e, tampouco, um conceito chave "que abra as portas”, que consiga analisar situações psíquicas, existencial, social, econômica e política. (Mercadante, 2005, p. 23) 
Morin vem nos alertando para o fato de cotidianamente, sermos confrontados com o desafio da complexidade. Por isso nossa tarefa neste trabalho foi compreender como cada personagem - ao evocar, narrar e atribuir sentido às suas experiências - portou-se diante da mudança brusca no roteiro de suas vidas, como teceu seus corolários morais e interpessoais, para, então, poder reconstituir sua narrativa.

Além de enfrentar as mudanças de sua fase de desenvolvimento, os protagonistas desta investigação sofreram com a perda de sua condição socioeconômica. Eles não acreditavam que empobrecer seria um fato real em suas idas e, portanto, não buscaram formas de proteção financeira que lhes assegurassem um envelhecer sem problemas dessa ordem.

Das aprendizagens construídas pelos sujeitos ao longo do seu processo de envelhecimento, especialmente com o impacto do empobrecimento na velhice, observamos que o Grupo B, por transitar em outros contextos diferentes de A, assimilou com menos dificuldades a queda no padrão financeiro, pois conhecia a realidade do trabalho como meio de promoção de qualidade de vida e visualizava melhor a possibilidade de adaptar-se ao contexto situacional. Já o Grupo A ignorava a possível ocorrência de qualquer adversidade que pudesse modificar o rumo de sua trajetória de vida: afinal, desconhecia qualquer outra realidade que não aquela onde todos os desejos eram passíveis de realização.

Tais diferenças de visão de mundo determinaram a forma como cada grupo vivenciou o impacto da perda financeira. $O$ Grupo B sentiu o baque, cambaleou, porém, manteve-se em pé devido a algumas precauções por parte de seus membros: havia a preocupação de pagar o INSS, vender e comprar imóveis de maneira a lucrar com a negociação, guardar "um dinheirinho" no banco para uma eventual emergência. Por sua vez, para o 
Grupo A, a queda brusca de padrão de vida foi sentida como a "perda do chão", a incerteza do desconhecido, o despreparo para uma eventualidade e, portanto, o desmoronamento total.

Superar o impacto da mudança radical não foi tarefa fácil para nenhum dos entrevistados. Contudo, aqueles que possuíam uma rede social fortalecida receberam mais apoio para reformular seu projeto de vida e demonstraram maior capacidade de adaptação à nova situação, independentemente da classificação dos grupos aqui adotada. Importante destacar a importância do apoio advindo dos filhos, assinalada por quatro dos seis entrevistados.

Conforme salienta Sluski (1997), ao envelhecer o sujeito sofre mais perdas em sua rede social pessoal e encontra menos oportunidades de substituição de vínculos. Assim, as pessoas mais velhas se vêem cada vez mais restritas apenas às suas relações familiares. Decorre então que as relações que permanecem sofrem uma sobrecarga de valorização $e$, portanto, as relações entre filhos e pais idosos adquirem novas e complexas dinâmicas.

De modo geral, os pertencentes ao Grupo B demonstraram ter recebido ajuda de familiares, amigos e membros de comunidades religiosas e sociais. Interessante notar que, apesar de receberem com carinho e alegria o apoio dos familiares, o fato de possuir uma renda que possibilita suprir os gastos pessoais e manter sua própria casa garante aos entrevistados certo tipo de liberdade que valorizam e fazem questão de manter. Os filhos são bem-vindos como base de segurança emocional e, eventualmente, como possíveis fontes de socorro financeiro.

Já alguns membros do Grupo A experimentaram sérias restrições em suas redes sociais após a perda financeira. Os 
relatos demonstram a desestruturação da identidade social e o sentimento de isolamento proveniente do fato de não poder participar das mesmas atividades sociais habituais devido à falta de recursos materiais. As relações familiares também foram abaladas e o recebimento de ajuda financeira dos parentes mais próximos despertou sentimentos negativos, fato que acreditamos manter estreita relação com a questão da identidade social, uma vez que a necessidade de ajuda reafirma a condição de incapacidade para manter suas despesas mais básicas e desperta a condição de submissão entre aquele que ajuda e aquele que recebe, instalando-se aí a dependência econômica.

Sobre a questão da dependência na velhice, Quaresma (2006, p. 37) assinala que:

a categorização da dependência, a desvalorização da velhice "dependente", a solidão que a acompanha, representam formas de privação do sentido, do sentido da velhice como fase da existência humana. E, como tal, são elos da cadeia que liga categorização, déficits de conhecimento, déficits de relação, representações sociais de velhice (medos, irracionalidades, preconceitos).

O conceito de dependência é uma construção social que vem sustentando cada vez mais políticas de proteção social no Brasil a favor de pessoas com maior vulnerabilidade. No entanto, concordamos com Quaresma ao dizer que não há pessoas dependentes, mas sim pessoas com situações de dependência. $\mathrm{E}$ essas situações ocorrem em qualquer fase da vida, embora reconheçamos que as pessoas idosas, por viverem mais anos, têm uma exposição maior aos riscos, sejam eles biológicos, culturais e/ou financeiros.

Concordamos novamente com Quaresma (2006) que o envelhecimento é fortemente condicionado pelas capacidades de adaptação ao longo da vida e que estas não dependem 
apenas, nem tampouco, de fatores individuais. E que as práticas culturais indiciam uma melhor superação dos problemas, facilitando a comunicação e as relações interpessoais.

A vivência da espiritualidade apareceu como ferramenta importante para o enfrentamento da queda no status econômico e social. Para cinco dos seis entrevistados, acreditar em algo maior que a própria existência, quer seja a bondade da humanidade, quer seja a força de um Ser Superior, proporciona-lhes certo sentimento de segurança, de que "não será abandonado" ou de que precisava aprender algo com a experiência que lhe foi imposta. $O$ medo em relação ao futuro inexiste para aqueles que relatam algum tipo de fé ou espiritualidade. Por outro lado, a única entrevistada que não fez qualquer menção sobre algum tipo de crença espiritual ou religiosa foi exatamente aquela que relatou sentir o impacto da perda financeira como um evento catastrófico e insuperável. Afirmou não ser capaz de adaptar-se à nova situação, mantendo-se totalmente dependente da ajuda financeira de sua mãe e de seus filhos para conseguir obter seu sustento.

Tais explanações nos levam a considerar que o impacto ocasionado pelo empobrecimento em idosos que gozavam de uma situação financeira abastada foi sentido em maior ou menor intensidade, dependendo do tipo de trajetória de vida construída pelos sujeitos. Aqueles que cultivaram uma rede social apoiada em múltiplos eixos demonstraram possuir uma maior capacidade de adaptação aos eventos estressores provenientes das reviravoltas do projeto de vida e aparentaram uma facilidade maior em aceitar e assimilar as lições da vida. 


\section{Referências}

BORN, C. Gênero, trajetória de vida e biografia: desafios metodológicos e resultados empíricos. Sociologias, v. 3 n. 5, p. 240-265, 2001.

CAMARANO, A. A.; KANSO, S.; MELLO, J. L. Como vive o idoso brasileiro. In: CAMARANO, A. A. (Org.). Os novos idosos brasileiros: muito além dos 60? Rio de Janeiro: IPEA, 2004.

DEBERT, G. G. As representações (estereótipos) do papel do idoso na sociedade atual. In: SEMINÁRIO INTERNACIONAL ENVELHECIMENTO POPULACIONAL. Anais do Primeiro... Brasília, 1996. p. 35-45.

A construção e a reconstrução da velhice: família, classe social e etnicidade. In: NERI, A. L.; DEBERT, G. G. (Orgs.). Velhice e sociedade. Campinas: Papirus, 1999.

HOLLIS, J. A passagem do meio: da miséria aos significado da meiaidade. São Paulo: Paulus, 1995.

MAY, T. Pesquisa social: questões, métodos e processos. Porto Alegre: Artmed, 2004.

MERCADANTE, E. F. Velhice: uma questão complexa. In: CORTE, B.; MERCADANTE, E. F.; ARCURI, I. G. (Orgs.). Velhice, enveIhecimento complex(idade). São Paulo: Vetor, 2005. p. 23-34.

MORIN, E. Epistemologia da complexidade. In: SCHNITMAN, D. F. (Org.). Novos paradigmas, cultura e subjetividade. Porto Alegre: Artes Médicas, 1996. p. 274-286.

NERI, A. L. Qualidade de vida no adulto maduro: interpretações teóricas e evidências de pesquisa. In: NERI, A. L. (Org.). Qualidade de vida e idade madura. Campinas: Papirus, 1993.

O fruto da semente: processos de amadurecimento e envelhecimento. In: NERI, A. L. (Org.). Maturidade e velhice: trajetórias individuais e socioculturais. Campinas: Papirus, $2001 a$.

Paradigmas contemporâneos sobre o desenvolvimento humano em Psicologia e Sociologia. In: NERI, A. L. (Org.). Desenvolvimento e envelhecimento: perspectivas biológicas, psicológicas e sociológicas. Campinas: Papirus, 2001b.

NERI, A. L.; FREIRE, S. A. Qual é a idade da velhice? In: NERI, A. L.; FREIRE, S. A.(Orgs.). E por falar em boa velhice. Campinas: Papirus, 2000. 
NERI, A. L.; YASSUDA, M. S. Apresentação. In: NERI, A. L. ; YASSUDA, M. S. (Orgs.). Velhice bem-sucedida: aspectos afetivos e cognitivos. Campinas: Papirus, 2004.

PASCHOAL, S. M. P. Qualidade de vida do idoso: construção de um instrumento de avaliação através do método do impacto clínico. Tese (Doutorado) - Faculdade de Medicina da Universidade de São Paulo, São Paulo, 2004.

PEIXOTO, C. E. Aposentadoria: retorno ao trabalho e solidariedade familiar. In: PEIXOTO, C. E. (Org.). Família e envelhecimento. Rio de Janeiro: Editora FGV, 2004a.

Processos diferenciais de envelhecimento. In: PEIXOTO, C. E. (Org.). Família e envelhecimento. Rio de Janeiro: Editora FGV, 2004b.

QUARESMA, M. L. Gerontologia e Gerontologia Social. Kairós, v. 9, n. 1, p. 19-42, 2006.

SLUZKI, C. E. A rede social na prática sistêmica: alternativas terapêuticas. São Paulo: Casa do Psicólogo, 1997.

SMITH, J. Well-being and health from age 70 to 100: findings from the Berlim Aging Studt. European Review, v. 9, n. 4, p. 461-477, 2001.

VELHO, G. Nobres e anjos: um estudo de tóxicos e hierarquia. Tese (Doutorado) - Faculdade de Filosofia, Letras e Ciências Humanas da Universidade de São Paulo, São Paulo, 1975.

VELOZ, M. C. T.; NASCIMENTO-SCHULZE, C. M.; CAMARGO, B. V. Representações sociais do envelhecimento. Psicol. Reflex. Crit., v. 12, n. 2, p. 479-501,1999.

VERAS, R. P.; RAMOS, L. R.; KALACHE, A. Crescimento da população idosa no Brasil: transformações e conseqüências na sociedade. Revista de Saúde Pública, v. 21, n. 3, p. 225-233, 1987.

WALSH, F. A família no estágio tardio da vida. In: CARTER, B.; MCGOLDRICK, M. (Org.). As mudanças no ciclo de vida familiar: uma estrutura para a terapia familiar. Porto Alegre: Artes Médicas, 1995.

Fortalecendo a resiliência familiar. São Paulo: Roca, 2005. 